\title{
A Case in Point: \\ Individual Library Instruction for International Students
}

\author{
by Nan Watkins
}

$\boldsymbol{W}$ estern Carolina University, a small comprehensive regional campus with a student enrollment of approximately six thousand, is one of the sixteen senior institutions of the University of North Carolina. It is situated in the unincorporated village of Cullowhee in the Blue Ridge Mountains. With an international student population of less than two percent of the student body, why would our library reference staff make it a priority to support individualized bibliographic instruction for students from other countries?

A majority of our international students are graduate students, and most come from Asian and African countries. Almost none have experience using American libraries, and many have limited ability using the English language. A minority of students come from Europe and South America with varying degrees of command of written and spoken English. When left on their own in our library, most of these students do not know where to begin. When I first joined the library staff thirteen years ago, a few international students managed to join our regular library tours for freshmen, but they profited little because of their limitations with the English language and their lack of experience in American libraries. They were hesitant to come to the Reference Desk for help; when they did come, the staff had trouble understanding their requests, and the students often did not have the background to comprehend the librarian's reply. Despite these hardships, the international students remained persistent in their attempts to do library assignments and research, and the librarians remained unsatisfied with their ability to give them meaningful help. Something had to be done.

The staff of our Reference Department identified the specialized needs of international students some ten years ago. We came to realize that our roughly one hundred international students were among the most dedicated and extensive users of the library. Because we are a small school, we felt that having one librarian take extra time at the beginning of each semester to give the approximately twenty new international students individualized library instruction would be an efficient way to put the foreign students on a near-equal footing with their American classmates. We hoped that by giving the international students this specially designed library instruction, the future interactions between foreign students and library staff would be more effective, more sophisticated, and more rewarding for all concerned.

Having been a foreign student myself, I offered to develop a special orientation program tailored to the individual needs of our international students. When I began developing this program, I turned to the literature to see what help and advice were available. One of the first studies on international students' library orientation was published in 1969 by Mary Lewis. A few articles appeared each year during the 1970 s. Then, the 1980 s saw a large increase in foreign student enrollment with a corresponding increase in library literature dealing with this new challenge for librarians. Early in 1995, Allen Natowitz examined eighteen articles written over the previous ten years and put into perspective the current state of orientation for international students. The articles ranged from practical suggestions on how to present new material to foreign students, to special classroom instruction for these students, to statistical studies of the effectiveness of various programs. Nowhere did I find a guide to individualized instruction. Thus, it was with a combination of personal experience and reading the published literature that I developed a program that suited the needs of the students and staff at our library.

International students require that we understand their different worlds of experience. We must remember that they come from different cultural backgrounds and have different social standards from our own. For students who have just flown in from a distant foreign country, the culture shock is great. They must deal immediately with a foreign immigration service, a foreign language, foreign money, a foreign calendar, and a foreign educational system. They must adjust to many subtle changes in daily life: different expectations concerning punctuality and different ways of interacting with people, including different roles for men and women. When things get rough, they become homesick for their native countries, their own foods, and their own places of religious worship. Yet, these students know that they and their families have made great sacrifices for them to come to the United States for an education, and they want to make the most of their time here.

Our goal for these new international students was to help them become proficient in the basic skills required for using our university library for their graduate or undergraduate studies. It was agreed that this would mean the students should know the layout of the library; have a fundamental understanding of the LC classification scheme and what a call number is; have the ability to use the OPAC to find a book; understand how to use a periodical index to find an article; know how to locate the book and article on the library shelves; be 
introduced briefly to those automated and paper resources that would be appropriate to the students' fields of study; know how to operate the copy machines and how to check out circulating materials; know when to ask the librarian for help when they were unable to locate what they needed.

During the past ten years that I have given instruction to our international students, I have refined the technique and made changes when new technology and resources required them. Despite the great changes that have taken place in college and university libraries during that time, four steps remain basic to the instruction. They are as follows:

1. Identify the new international students at the beginning of each semester.

2. Meet the students as a group and give them written invitations for their individualized instruction.

3. Interview the students briefly when they come to the library to make their appointments for instruction.

4. Give a library tour and instruction tailored to the needs of the individual foreign students.

Before discussing these four steps, let me mention a few general techniques that I have found effective in working with international students:
The first step of identifying the new students is achieved with the help of the Director for International Students. At the beginning of each semester, I attend the required Special Orientation for International Students held the weekend before classes begin. There I meet all the new students, get a list of their names, addresses, and phone numbers from the Director, and have the chance to talk with them informally. I speak briefly to the group as a whole, emphasizing the importance of library assignments in their upcoming education in the United States. I encourage the students to come for their instruction alone or with fellow students from their own country. During the first week of classes, each student is given a written invitation to come to the Reference Department to make an appointment with me for library instruction. I find that a large majority of new students dutifully report. The few remaining students, too shy or too busy or confused to come by, I contact again, so that in the end nearly all international students receive instruction.

When the students come to make their appointments, I use the opportunity to conduct a brief interview with each one; this helps me to determine his or her language skills, course of study, and level of previous library experience. Ask-
- Plan to instruct from one to a maximum of four students at a time; when there is more than one student, it is preferable that they be from the same country. Two or three is a good number for students who have low language skills, for they can help each other understand new concepts in their native language. If there are more than four students, they do not get much hands-on experience, and they receive less individual attention.

- Speak clearly, perhaps a bit more slowly than usual, and do not use slang or jargon. Do not make jokes unless your students are excellent speakers of English. It is not necessary to raise your voice.

- Do not lecture, but converse with the students, asking frequent questions that require responses. The fact that the students often nod their heads while you talk does not mean that they understand what you are saying.

- Carry a plain piece of paper and a pen while giving the tour and instruction, and write down important words which are not familiar to the students. They master new vocabulary more easily when simultaneously seeing and hearing the words.

- Give the students as much hands-on experience as possible. It is helpful to stand with your hands behind your back when demonstrating machines so that the students will have the experience of doing things for themselves.

- Be selective about what you choose to show the students, and avoid overwhelming them with too much information in a short period of time. Limit each session to one hour.

- Sharpen your listening skills to be alert to various foreign accents. If you cannot understand what a student says, ask him/her to write it down.

- Keep patience and good humor in generous supply.
We want them to know our staff is very service-oriented and ready to help them with their library research. This is usually in contrast to what many of them have experienced in their libraries back home.

ing them to tell a little about their backgrounds and study interests helps to put them at ease and gives them the opportunity to talk about subjects that pose no threat to them. This is also a wonderful chance to learn about library practices around the world. We make an appointment to meet, and I give each student a written slip stating the date, time, and place we will meet. After the student leaves, I jot down the pertinent information I need to plan my initial strategy for instruction. If the student is from a remote university in western China, for example, with no experience in using open stacks, in typing, or in using machines found in our library, I plan several separate hour-long sessions. If a student is from the Netherlands with an excellent command of English and with a more sophisticated library-use background, I plan a tour and instruction which can probably be completed in one good session.

I always begin the library tour at our kiosk showing the library floor plan and highlighting the areas pertinent to the needs of the particular students. At this point, I give a brief discussion of our general philosophy of library use - that we aim to give all students the basic skills to be self-reliant in doing routine library operations. We also want them to know our staff is very service-oriented and ready to help them with their library research. This is usually in contrast to what many of them have experienced in their libraries back home. With this in mind, we take a walking tour of the library, and I introduce the students to library staff whenever possible. These introductions not only help break down the barrier of formality which many foreign students feel toward staff, but they 
also give staff members a moment of personal contact so that future exchanges with the students run more smoothly.

At the point at which I show the students the reference collection, I ask them what a call number is. Because they rarely know the answer, I have an opportunity to give them a one-page outline of the LC classification system. We begin with the letters $\mathrm{AE}$ at the general encyclopedias and then continue through a few more letters - AY, B, BF, BL, etc. - until they get the general idea of how the letters aid in arranging the books by subject. Then we jump to the section of the student's major - the Ts and technology, for example - so that by actually seeing the books and circling the call number on the LC classification outline, the students will remember where to go for their chief reference needs. At this time, I also show a few examples of subject encyclopedias, saying they are generally shelved at the beginning of each new call number. These encyclopedias are excellent tools for students who do not have the background of an American education and who need help in developing their English vocabularies.

After touring the reference section, we move around the library through the current, bound, and microfilm periodicals, taking enough time for the newly arrived students to master the necessary jargon, and stopping by the various copy machines to teach the students what a nickel is and how to purchase a debit card and make copies. We visit the periodical indexes and the various CD-ROM

stations, where I explain only general concepts and point out specific indexes and databases which would be of use to the students. We end the tour visiting the circulating collection, the circulation desk, and any other particular departments of the library such as the Map Room, Government Documents, or Curriculum Library, which would be pertinent to the students concerned.

The second phase of the orientation becomes more specific, with instruction on the OPAC and periodical indexes. The level of instruction is geared to the experience of the students. For those students who are unfamiliar with computers, the instruction may require patient attention while they try their hand at locating sources in their fields. With automated sources changing so frequently, I try to introduce the concepts of navigating through the online system, emphasizing the importance of being observant about where, and in which database, the student currently is. For those with little experience with computers, I recommend that they make time for short, frequent practice sessions in the first weeks of school, so that they begin to feel at home with the new system before the crunch of term papers comes. The minimum goal of this session is to enable the students to find a book, with the aid of the LC Subject Headings in their major field of study; to know how to use both a paper and an automated periodical index (InfoTrac); and to have an overview of the various off-campus resources available to them. When the students have located the citations for a book and a periodical article in their various fields, they are asked to find the book and the article on their own and to bring them back so we can examine them together. We discuss briefly the bibliography, abstract, index, and any other salient features, helping the students to evaluate the fund of information they have found.

It remains surprising to me how difficult this final assignment of finding a book and an article can be. It becomes the test of how much the students have comprehended in both the tour and the instruction and how well the librarian has communicated with them. It is humbling for the librarian to realize how necessary it is to be clear, concise, focused, and perceptive of the students' response during the actual instruction.

I n conclusion, I can say that our reference staff is unanimous in wishing to continue this special instruction. We have found that individualized instruction for the international students at our small school is well worth the time and effort invested. It yields a far more productive working relationship between student and librarian than any group instruction we have tried. Our ability to help the international students surmount their "handicaps" of no American schooling and not having English as a native language gives large rewards in the form of seeing them progress and flourish in their university experience in this country. Feeling at ease in the library is the key that gives these students confidence in their studies, which, in turn, is crucial to their integration into campus life as valued university citizens who have much to offer us all. For the librarian privileged to give international students individual instruction, the rewards are great. In the vast majority of cases the students are highly motivated to learn, and they are quick and generous in showing their gratitude for guidance received.

\section{Select Bibliography}

Allen, Mary Beth. "International Students in Academic Libraries: A User Survey." College \& Research Libraries 54 (July 1993): 323-333.

Ball, Mary Alice and Molly Mahony. "Foreign Students, Libraries, and Culture." College \& Research Libraries 48 (March 1987): 160-166.

Bilal, Dania M. "International Students' Acquisition of Library Research Skills: Relationship with their English Language Proficiency." The Reference Librarian No. 24 (1989): 129-145.

Boers, Greta G. "Designing a Library Instruction Program for International Students." The Georgia Librarian 31 (Winter 1994): 92-95.

Brock, Barbara. "Library Skills for International Students: From Theory to Practice." In Bibliographic Instruction and the Learning Process: Theory, Style and Motivation, edited by Carolyn A. Kirkendall. Ann Arbor: Pierian Press, 1984.

Burhans, Skip. "Serving the Information Needs of the International and Minority Students at the Small College Library: A Librarian's View." ERIC Document ED 335 714, April 1991. 
Chau, May Ying and Michael Culbertson. "Library Services for International Students: a Study at Colorado State University." Colorado Libraries 20 (Fall 1994): 40-41.

Chen, Chiou-sen. How to Use Academic Libraries in the United States. Hong Kong: Joint Publishing Co., 1987. [In Chinese]

Cope, Johnnye and Evelyn Black. "New Library Orientation for International Students." College Teaching 33 (Fall 1985): 159-162.

Feldman, Dick. "The International Student and CourseIntegrated Instruction: the ESL Instructor's Perspective." Research Strategies 7 (Fall 1989): 159-166.

Garcha, Rajinder and Patricia Yates Russell. "Bibliographic Instruction for International Students in Academic Libraries." Library Review 42 (no. 6 1993): 14-22.

Goudy, Frank, and Eugene Moushey. "Library Instruction and Foreign Students: A Survey of Opinions and Practices Among Selected Libraries." The Reference Librarian No. 10 (Spring/Summer 1984): 215-226.

Graves, Gail T. and Barbara Adams. "Library Instruction and Cultural Diversity: Programming in an Academic Library." Mississippi Libraries 57 (Winter 1993): 99-101.

Greenfield, Louise W. "Training Library Staff to Reach and Teach International Students." In Reaching and Teaching Diverse Library User Groups: Papers Presented at the Sixteenth National LOEX Library Instruction Conference, edited by Teresa B. Mensching. Ann Arbor: Pierian Press, 1989. LOEX-88.

Hagey, A. R. and Joan Hagey. "Meeting the Needs of Students From Other Cultures." Improving College and University Teaching 22 (Winter 1974): 42-44.

Hendricks, Yoshi. "The Japanese as Library Patrons." College \& Research Libraries News 51 (April 1991): 221-225.

Hoffman, Irene and Opritsa Popa. "Library Orientation and Instruction for International Students: The University of California-Davis Experience." RQ 25 (Spring 1986): 356-360.

Jacobson, Frances F. "Bibliographic Instruction and International Students." Illinois Libraries 70 (December 1988): 628-633.

Kflu, Tesfai and Mary A. Loomba. "Academic Libraries and the Culturally Diverse Student Population." College \& Research Libraries News 54 (June 1990): 524-527.

Kline, Laura S, and Catherine M. Rod. "Library Orientation Programs for Foreign Students: A Survey." RQ 24 (Winter 1984): 210- 216.

Koehler, Boyd and Kathryn Swanson. "ESL Students and Bibliographic Instruction: Learning Yet Another Language." Research Strategies 6 (Fall 1988): 148-160.

Lewis, Mary Genevieve. "Library Orientation for Asian College Students." College \& Research Libraries 30 (May 1969): 267- 272.

Liestman, Daniel. "Implementing Library Instruction for International Students." PNLA Quarterly 56 (Winter 1992): 11-14.

Liestman, Daniel and Connie Wu. "Library Orientation for International Students in their Native Language." Research Strategies 8 (Fall 1990): 191-196.

Liu, Ziming. "Difficulties and Characteristics of Students from Developing Countries in Using American Libraries."
College \& Research Libraries 54 (January 1993): 25-31.

Lopez, Manuel D. "Chinese Spoken Here: Foreign Language Library Orientation Tours." College \& Research Libraries News 44 (September 1983): 265-269.

Macdonald, Gina and Elizabeth Sarkodie-Mensah. "ESL Students and American Libraries." College \& Research Libraries 49 (September 1988): 425-431.

Mood, Terry Ann. "Foreign Students and the Academic Library." RQ 22 (Winter 1982): 175-180.

Moorhead, Wendy. "Ignorance Was Our Excuse: BI for Foreign Students Requires a Shift in Cultural Perspective." College \& Research Libraries News 47 (October 1986): 585-587.

Natowitz, Allen. "International Students in U.S. Academic Libraries: Recent Concerns and Trends." Research Strategies 13 (Winter 1995): 4-16.

O'Hara, Molly. "Bibliographic Instruction for Foreign Students." In Academic Libraries: Myths and Realities. Proceedings of the Third National Conference of the Association of College and Research Libraries, edited by Suzanne C. Dodson and Gary L. Menges. Chicago: ACRL, 1984.

Ormondroyd, Joan. "The International Student and CourseIntegrated Instruction: The Librarian's Perspective." Research Strategies 7 (Fall 1989): 148-158.

Osborne, N. S. and M. H. Maier. "Service to International Users: The Case of a Brazilian Biologist." Research Strategies 10 (Spring 1992): 84-87.

Pearson, Richard C. and Rex Frandson. "Library Instruction in a Multi-Cultural Setting." Hawaii Library Association Journal 40 (1983): 33-36.

Penchansky, Mimi B., ed. International Students and the Library: An Annotated Selective Bibliography on the Theme of the LACUNY 1988 Institute. New York: The Library Association of the City University of New York, 1988.

Roberts, Anne F. "Indonesians in the Library: Unity in Diversity, or, One Library's Experience." The Bookmark 45: (Fall 1987) 42-46.

Sarkodie-Mensah, Kwasi. "Dealing with International Students in a Multicultural Era." The Journal of Academic Librarianship 18 (September 1992): 214-216.

"In the Words of a Foreigner." Research Strategies 4 (Winter 1986): 30-31.

Spanfelter, Deborah L. "Teaching Library Skills to International Students." Community \& Junior College Libraries 7 (no.2 1991): 69-76.

Wayman, Sally. "The International Student in the Academic Library." Journal of Academic Librarianship 9 (January 1984): 336-341.

"The International Student in Your Library: Coping with Cultural and Language Barriers." In Bibliographic Instruction and the Learning Process: Theory, Style and Motivation, edited by Carolyn A. Kirkendall. Ann Arbor: Pierian Press, 1984. 